\title{
Research Paper: Virtual Reality Practice, Computer Games, and Improvement of Cerebral Palsy Balance: A Single Subject Study
}

\author{
Samira Boroumand ${ }^{1}$, Afsoon Hassani Mehraban ${ }^{2 *}$, Mahdi Dadgou ${ }^{3}$, Parvin Raji $^{4}$
}

1. Master Student, Department of Occupational Therapy, School of Rehabilitation Sciences, Iran University of Medical Sciences, Tehran, Iran.

2. Associate Professor, Department of Occupational Therapy, School of Rehabilitation Sciences, Iran University of Medical Sciences, Tehran, Iran.

3. Assistant Professor, Department of Physical Therapy, School of Rehabilitation Sciences, Iran University of Medical Sciences, Tehran, Iran.

4. PhD Candidate, Department of Occupational Therapy, School of Rehabilitation, Tehran University of Medical Sciences, Tehran, Iran.

Article info:

Received: 28 Jun. 2016

Accepted: 12 Oct. 2016

\section{Keywords:}

Virtual reality, Balance, Child, Cerebral palsy
Citation: Boroumand S, Hassani Mehraban A, Dadgou M, Raji P. Virtual Reality Practice, Computer Games, and Improvement of Cerebral Palsy Balance: A Single Subject Study. Journal of Modern Rehabilitation. 2017; 11(1):23-30. https://doi. org/10.18869/nirp.jmr.11.1.23

https://doi.org/10.18869/nirp.jmr.11.1.23 


\section{Introduction}

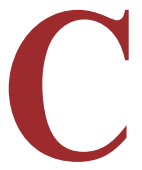

erebral palsy is one of the most common causes of physical disability in the first few years of life. Despite technological advances in the neonatal intensive care units and improvement in prenatal care in the past two decades, it still remains as one of the main causes of childhood developmental disorder [1]. Its prevalence is 2-3 cases per 1000 live births [2]. This disorder creates many problems in children such as paralysis, weakness, sensory abnormalities, and a variety of deformities [3]. Impaired balance and postural control is one of the key problems in patients with cerebral palsy. Balance is needed to perform many daily activities [4]. It helps children against many sudden injuries following slipping, falling and so on [5].

Studies indicate that children with cerebral palsy are able to stand and walk independently (or without aid tools) compared to healthy peer children and they have more center of pressure fluctuations, they take step against fewer perturbation and need more time for obtaining stability. Also, they have unsuitable pattern and timing of muscle contraction. Collection of these points confines ability to walk and balance in people with cerebral palsy and makes them more vulnerable to falling and injury [6]. Thus, balance improvement is one of the main goals in rehabilitation of people with cerebral palsy [7].

Attraction and motivation in selected training for rehabilitation of children should be always considered. Selected training in treatment should be adequately attractive and motivating so that children are encouraged to actively participate in performances and repetition of exercises [8], of repetition exercises, active participation and use of purposeful movements are basic components in motor learning [9]. But since rehabilitation process is a long process for most diseases, therapists are challenged in finding various and motivating health training that has the ability to adapt and is able to facilitate this process [10]. Virtual reality is new computer technology which has been recently extended in rehabilitation and it is increasingly used [11].

This technology is able to create attractive and motivating activities for active participation of patients in treatment sessions. It not only develops opportunity for implementing real exercises in virtual and safe environment, but also it provides opportunity for involvement in purposeful, meaningful and enjoyable tasks that are related to activities of daily living for participants [11, 12]. In such environment, it is possible to change difficulty of exercise performance according to ability of individuals and make them more complicated or easier. In addition, clients can measure their activity results, be informed of their performance [13].

Many studies have shown positive impact of this technology in rehabilitation of adult with stroke [14], Parkinson [15], Multiple Sclerosis [16] and head injury [17]. However, a limited number of studies investigated influence of virtual reality on improvement of balance in children with cerebral palsy [18]. Case report by Detusch (2008) for the first time showed positive impact of virtual reality exercises to improve balance and postural control of a teenager with diplegia [19]. This finding was also obtained in clinical trial study by Gomez et al. (2011) for improvement of balance in people with hemiparesis and head injury so that finally they mentioned capability of replacement of traditional treatments with computer games as a safe, comfortable, fun and effective treatment [20].

Considering these findings and given limited number of studies on rehabilitation of balance in children with cerebral palsy using virtual reality and lack of study on long term durability of treatment effect ( 3 months), necessity for designing a study in this regard is evident. Thus, current study aims at defining impact of implementing exercises in virtual reality on balance in children with cerebral palsy.

\section{Materials and Methods}

\section{Participants}

Current study was implemented in school of rehabilitation sciences, Iran University of Medical Science in 2014. Inclusion criteria were: 1. Having cerebral palsy; 2. Age range of 7 to 12 years; 3 . Having normal intelligence (the ability to study at regular schools); 4. Ability to independently stand for 5 minutes; 5 . Ability to walk independently without assistive devices; and 6 . Full foot contact with the ground when standing. Also, exclusion criteria included as follows: 1. Uncorrectable problems with hearing or vision with aids; 2. Lack of cooperation with the researcher; 3. Persistence seizure, 4. Single foot standing for more than 10 seconds. Three children with cerebral palsy (10.37 \pm 2.93$)$ participated in the current study.

The first child was 12 years and 3 months old with right hemiplegia. The second child was 11 years and 8 months old and with left hemiplegia. The third one was 7 years old and with right hemiplegia. All of these people entered research phases following completing written consent form (by parents) and initial demographic form. It 
should be noted that this study was approved by Ethics code 93/d/105/5532 in Ethics Committee of the School of Rehabilitation, Iran University of Medical Sciences.

\section{Procedures}

Case study (ABA) with 2-3 month follow up was considered for the current study. Evaluations were done in three phases by one therapist: 1 . Initial evaluation - 4 sessions with 3 repetition per week for about 2 weeks; 2 . Intervention phase - 12 sessions with 3 repetitions per week during 4 weeks; 3 . Follow up phase - 1 sessions, 2-3 months after completion of intervention phase. The number of initial phase was determined considering ethical issues and pilot study results done with a 4.5 years old child with cerebral palsy. Pediatric Reach Test (PRT), Timed Up and Go (TUG), 10 - Meter Walking(10MW) tests were implemented in all phases and subset of balance and lower limb strength test including Bruiniks_oseretsky of motor proficiency (BOMP) was implemented once in initial evaluation phase, twice in intervention phase (sessions 6 and 12) and once in follow-up phase for recording changes.

\section{Materials and tools}

\section{Timed Up and Go}

It is suitable test for investigating functional mobility in healthy children and children with motor impairments. According to the period of time spent on getting up from a chair, passing over a distance of $3 \mathrm{~m}$, turning, returning the past path and sitting on the chair, its functional mobility and it has high validity and reliability (ICC: 0.99 ) for investigating functional mobility in children with cerebral palsy $[21,22]$.

\section{0 - Meter Walking}

It is a simple, quick and cheap test with acceptable reliability and validity in children with cerebral palsy which evaluates speed of walking. In this test, a $14 \mathrm{~m}$ distance is defined by marker and the child is asked to pass this path with easy and normal pace and 10 intermediate meters is recorded by the therapist using chronometer [23, 24].

\section{Pediatric Reach Test}

It is a simple, reliable and valid test for evaluating static balance in children with cerebral palsy which is implemented in two situations: sitting on the stool or standing. In this test, therapist investigates the balance according to the distance that the child can extend her hands forward without disturbing the balance and move the feet off the ground [25].

Subtest of balance and lower limb strength test (BOMP)

It is a standard, reliable and valid test which measures balance and lower limb strength within 9 separate parts [26].

\section{Biometrics Ltd E-link device}

It is a computer system with capacity to do multiple evaluations and implements treatment exercises in the form of defined games aiming at being used in rehabilitation clinics in England .Lower limb set (FP3 Dual-axis Force Plate System) in this device includes a 24 -inch screen and four power-sensitive screens with dimensions of $200 \times 125 \times 14 \mathrm{~mm}$ which are connected by cable to a central device [27].

\section{Intervention}

In this research intervention phase included 12 treatment sessions followed similar to initial evaluation phase with 3 repetitions per week. In each session, patients performed video exercises for 21 minutes using Biometrics Ltd E-link device. These exercises were simple and attractive games performed with center of pressure displacement and control in the frontal and sagittal planes and they were defined as uniaxial and biaxial in the system. Selection of suitable games was done based on the results obtained in pilot study and each patient performed 3 to 9 different games (driving, basket and ball, puzzle, golf, tennis, etc.) in each session. Level of each game was set according to the child's ability. The game steps were made more difficult in each session depending on the child's progress with change in speed or force needed for performing the game. Eight to twelve weeks after end of intervention sessions, all evaluations done in initial evaluation phase were measured within one assessment session and durability of treatment effects was investigated with the statistical comparison of this results with treatment phase results.

\section{Statistical analysis}

Visual analysis and C Static method were used for measuring changes during the research. Prior to analysis of data using these methods, investigation of serial dependency presence in data auto-correlation refers to the fact that frequent evaluations in performance of the person causes dependency in test results in each session and previous session so that performance of patient in 
Table 1. C statistics results of evaluated test

\begin{tabular}{|c|c|c|c|c|c|}
\hline Variable & Participant & $\mathrm{C}_{\mathrm{AB}}$ & $\mathbf{Z}_{\mathrm{AB}}$ & $\mathbf{P}$ & Interpretation \\
\hline \multirow{3}{*}{$\begin{array}{l}\text { Pediatric reach test } \\
\text { (Forward reach) }\end{array}$} & 1 & 0.94 & 4.04 & 0000 & Significant \\
\hline & 2 & 0.91 & 3.90 & 0000 & Significant \\
\hline & 3 & 0.85 & 3.64 & 0000 & Significant \\
\hline \multirow{3}{*}{$\begin{array}{c}\text { Pediatric reach test } \\
\text { (Lateral reach- healthy side) }\end{array}$} & 1 & 0.89 & 3.80 & 0000 & Significant \\
\hline & 2 & 0.87 & 3.75 & 0000 & Significant \\
\hline & 3 & 0.87 & 3.71 & 0000 & Significant \\
\hline \multirow{3}{*}{$\begin{array}{c}\text { Pediatric reach test } \\
\text { (Lateral reach- Injury side) }\end{array}$} & 1 & 0.57 & 2.44 & 0.0073 & Significant \\
\hline & 2 & 0.95 & 4.07 & 0000 & Significant \\
\hline & 3 & 0.87 & 3.74 & 0000 & Significant \\
\hline \multirow{3}{*}{10 Meter walking test } & 1 & 0.01 & 0.05 & 0.4801 & Not significant \\
\hline & 2 & -0.05 & -0.25 & 0.4013 & Not significant \\
\hline & 3 & 0.36 & 1.56 & 0.0594 & Not significant \\
\hline \multirow{3}{*}{ Timed up and go } & 1 & 0.22 & 0.97 & 0.166 & Not significant \\
\hline & 2 & 0.66 & 2.83 & 0.0023 & Significant \\
\hline & 3 & 0.38 & 1.63 & 0.0516 & Not significant \\
\hline
\end{tabular}

$* \mathrm{P}<0.05$

$J M R$

the next session can be predicted. In other words, presence of serial dependency in results of a test may imply that improvement in test results does not suggest intervention effect and it is consequence of repetition of test results. Thus, serial dependency was measured in results of all tests. No significant dependence was observed in the results of tests. Following this step, visual analysis and C Static was calculated for all tests.

\section{Results}

All participants completed research steps in complete safety situation and they suffered no physical damage during implementation of research steps. Investigation of information in initial evaluation phase using visual analysis and C Static test showed lack of significant changes in results of all tests and achievement of fixed pattern in changes. Comparison of results of pediatric reach test in initial and Intervention phase using $\mathrm{C}$ Static and visual analysis suggested significant improvement in ability of patients in three directions (injury side, healthy side, forward reach) of this test and durability of these results following treatment cut (Figure 1, 2, and 3; Table 1).

Investigation of results in BOMP test also showed improvement in results and durability of these effects following treatment cut (Table 2). Investigation of TUG test results using $\mathrm{C}$ Static showed significant changes in performance of patient 2 and durability of this change 11 weeks after end of intervention, while analysis of results for patients 1 and 3 showed no significant improvement (Table 1). Comparison of 10MW test results in initial evaluation phase and intervention phase using C. Static test suggested lack of significant changes in results of this test for all participants (Table 1).

\section{Discussion}

Balance is one of the situational control elements which is needed for implementing many of activities of daily living, social and recreational activities, at home, school and society by child. Deficiency in this ability is one of the key problems in children with cerebral palsy [4]. Thus, current study was designed and implemented

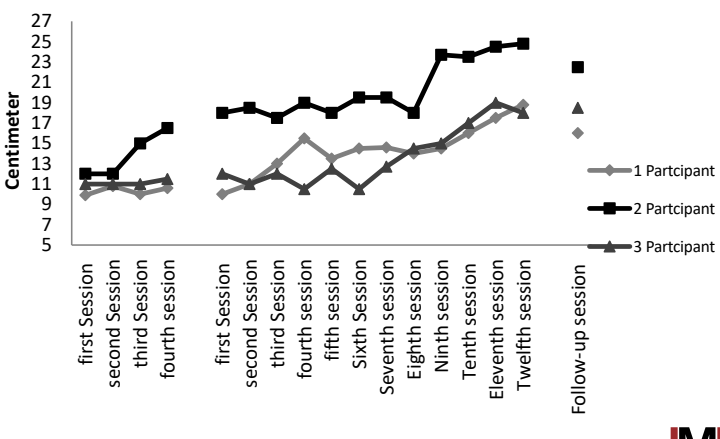

$J \mathrm{MR}$

Figure 1. Pediatric reach test results (lateral reach; healthy side) 


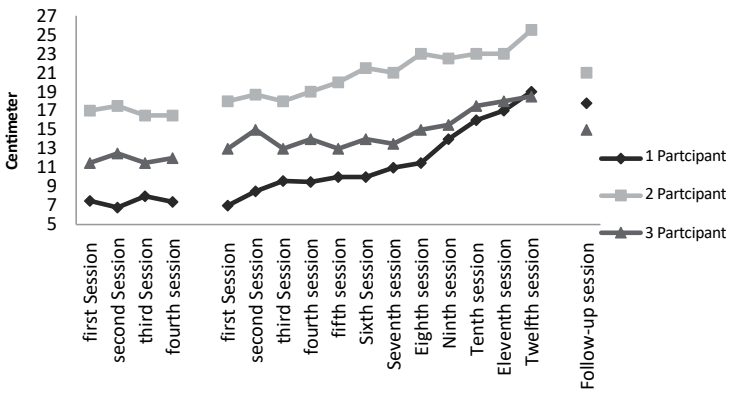

$J \mathrm{MR}$

Figure 2. Pediatric reach test results (forward reach; healthy side)

aiming at investigating influence of Implementing training in virtual environment on balance in children with cerebral palsy. Though virtual reality application in rehabilitation treatment of children with cerebral palsy has been increased, a limited number of studies investigated effect of running exercises using this technology on improvement of balance in children with cerebral palsy. In addition, none of them studied long term durability of treatment effects done in the current work.

In the current research, pediatric reach test and BOMP test were used for evaluating different aspects of balance and 10 meter walking and timed up and go tests were also considered for measuring possible changes made in speed and pace of walking and functional mobility. Also, according to the report by mother of child taking part in pilot study, BOMP test was used for measuring possible changes made in lower limb strength.

Investigation of balance test results in the patients suggested situational balance improvement in all participants. In addition, Hartveld and Hegarty showed implementing regular training for putting weight on two legs and weight displacement of the two feet in standing position can have a positive impact on improving the balance in children with cerebral palsy [28]. On the other hand, accompanying these exercises with virtual reality and in-

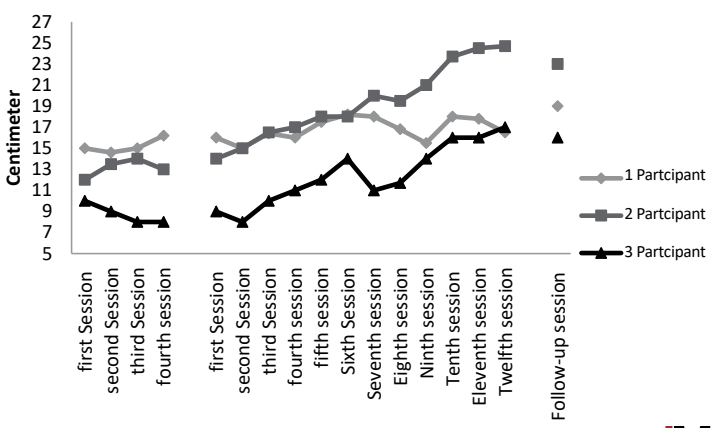

$J \mathrm{MR}$

Figure 3. Pediatric reach test results (lateral reach; injury side)

clusion of practices in the form of video games through creating joyful and funny environment distracts focus of children from repeating the identical movements and directs them to performing and progressing video games leading that children implement selective practices in longer time $[4,11]$.

Funny and attraction of virtual activities increases implementation of exercises in the form of video games and receiving various sensory feedbacks during and after ending games resulting in increased active participation and motivation of children in better performance[11, 29]. Hence, findings of the current work are consistent with those found by Brien [30], Deutsch [19], Luna-Oliva [18], Tarakci [4], JELSMA [29], and Morris [31] conducted using different balance tests in population of children with cerebral palsy. However, unlike findings in the current research, Ramstrand's work suggested lack of impact of implementing exercises in virtual reality on improvement of balance in children with cerebral palsy [32].

He studied the impact of implementation of 30-minute video games at home on balance for a period of 5 weeks in children with cerebral palsy. He performing exercises at home and lack of control over the type and duration of exercises which do by children as reasons for lack of achieving significant changes in balance. Also, there was

Table 2. Balance and strength results of Bruininks-Oseretsky test of motor proficiency (BOMP)

\begin{tabular}{|c|c|c|c|c|c|c|c|c|}
\hline \multirow{3}{*}{$\begin{array}{l}\text { Participant (Duration } \\
\text { of Follow up Phases) }\end{array}$} & \multicolumn{8}{|c|}{ BOMP Results } \\
\hline & \multicolumn{2}{|c|}{ Baseline Phases } & \multicolumn{2}{|c|}{$\begin{array}{l}\text { Intervention Phases } \\
\text { (6 Session) }\end{array}$} & \multicolumn{2}{|c|}{$\begin{array}{l}\text { Intervention Phases } \\
\text { (12 Session) }\end{array}$} & \multicolumn{2}{|c|}{ Follow up Phases } \\
\hline & Balance & Jump & Balance & Jump & Balance & Jump & Balance & Jump \\
\hline Participant 1 (9 weeks) & 14 & $61 \mathrm{CM}^{*}$ & 19 & $73 \mathrm{CM}$ & 20 & $68 \mathrm{CM}$ & 19 & $69 \mathrm{CM}$ \\
\hline Participant 2 (11 weeks) & 7 & $69 \mathrm{CM}$ & 12 & $76 \mathrm{CM}$ & 12 & $77 \mathrm{CM}$ & 12 & $74 \mathrm{CM}$ \\
\hline Participant 3 (11 weeks) & 9 & $34 \mathrm{CM}$ & 15 & $43 \mathrm{CM}$ & 14 & $56 \mathrm{CM}$ & 11 & $46 \mathrm{CM}$ \\
\hline
\end{tabular}


no suitable consistency in the group under study which can also influence such conclusion. Difference of the type and complexity of selected games in this study may also be reasons for making such conclusion by Ramstrand.

Investigation of BOMP test results also showed increased ability in transverse jump in participants in such a way that this improvement can be observed also in follow-up phase with some drop. Nagano et al. (2007) showed one of the basic needs for transverse jump is the ability to transfer center of gravity forward in the phase of separation of the foot from ground [33]. On the other hand, Samozinoet et al. stated the higher speed in separation of foot from the ground and higher force imposed in this phase, make the longer distance jump according to Newton's law of action-reaction [34]. Although exercises of the current work were not designed specifically aiming at jump improvement, sagittal plane games to some extent have been able to improve the speed and weight transfer skill on this plane and subsequently helped them to improve their jump by encouraging children to transfer weight and center of gravity forward and back ever faster and more complete.

However, implementation of more accurate experimental studies is needed for more obvious conclusion. In addition, Luna-Oliva (2013) found similar results using GMFM test in similar study [18]. He reviewed changes in walking, running and jumping ability in children with cerebral palsy after a two-month period (16 thirtyminute sessions) using Kinect device and showed virtual exercises can lead in significant improvement in gross motor skills such as jumping in children with cerebral palsy. Increase physical activity level of children was mentioned as reason for this improvement.

Analysis of changes made in speed of patients using 10-MW and TUG test suggested lack of significant changes in speed and functional mobility of patients. Although TUG test results for participants 2 showed speed improve, Considering the performance of all patients in two mentioned tests, it can be concluded that the interventions had not significant impact on improving walking speed of children with cerebral palsy. These results were consistent with findings of the case study of Siconolfi-Morris [31] on children with cerebral palsy and are not consistent with the results of the studies of Liao [35], Luna-Olivia [18] and Deutsch [19] in people with cerebral palsy, TATLA [17] in people with head injury, and Salem [11] in population with development delay.

In explaining differences between the results of this study and previous studies, this may be helpful that all patients participating in this study in contrast to previous studies were children with mild hemiplegic cerebral palsy and could walk with high speed. It was so that based on the results of the studies of Williams [21], their walking speed was in normal range. Therefore, to improve the walking speed, they needed more intensive, more complex and more specific exercises in the field of walking steps. While the type of selected exercises in this study have not been centralized specifically on walking speed and have only focused on displacement of the center of pressure in standing state between frontal and sagittal plates. Other walking stages such as lifting a limb and moving it to the front were excluded. Thus, it may be said that the difference in the ability level of participants and the type of selected exercises has led to achieve different results with previous studies.

This study showed that providing balance exercise using virtual reality influences balance improvement and jumping ability in children with cerebral palsy, but it does not influence walking speed in these children. Therefore, it can be used a safe, enjoyable and effective intervention in pediatric rehabilitation clinics and play significant role in promoting active participation of children in treatment sessions.

\section{Acknowledgements}

This research was extracted from the Master's thesis of Samira Boroumand, in the Department of Occupational Therapy, School of Rehabilitation Sciences, Iran University of Medical Sciences, Tehran and was financially supported by Iran University of Medical Sciences.

\section{Conflict of Interest}

The authors declared no conflicts of interest.

\section{References}

[1] Krägeloh-Mann I, Cans C. Cerebral palsy update. Brain and Development. 2009; 31(7):537-44. doi: 10.1016/j.braindev.2009.03.009

[2] Soleimani F, Vameghi R, Hemmati S, Biglarian A, Sourtiji H Survey on types and associated disorders of cerebral palsy in eastern and northern districts of Tehran. Archives of Rehabilitation. 2011; 12(3):75-82.

[3] Rosenbaum P, Paneth N, Leviton A, Goldstein M, Bax M, Damiano D, et al. A report: The definition and classification of cerebral palsy April 2006. Developmental Medicine \& Child Neurology. 2007; 109(109):8-14. PMID: 17370477 
[4] Tarakci D, Ozdincler AR, Tarakci E, Tutuncuoglu F, Ozmen $\mathrm{M}$. Wii-based balance therapy to improve balance function of children with cerebral palsy: A pilot study. Journal of Physical Therapy Science. 2013; 25(9):1123-7. doi: 10.1589/jpts.25.1123

[5] Woollacott MH, Shumway Cook A. Postural dysfunction during standing and walking in children with cerebral palsy: What are the underlying problems and what new therapies might improve balance. Neural Plasticity. 2005; 12(2-3):211-9. doi: $10.1155 / \mathrm{np} .2005 .211$

[6] Pavão SL, dos Santos AN, Woollacott MH, Rocha NACF. Assessment of postural control in children with cerebral palsy: A review. Research in Developmental Disabilities. 2013; 34(5):1367-75. doi: 10.1016/j.ridd.2013.01.034

[7] Kembhavi G, Darrah J, Magill Evans J, Loomis J. Using the Berg Balance Scale to distinguish balance abilities in children with cerebral palsy. Pediatric Physical Therapy. 2002; 14(2):92-9. doi: 10.1097/00001577-200214020-00005

[8] Harris K, Reid D. The influence of virtual reality play on children's motivation. Canadian Journal of Occupational Therapy. 2005; 72(1):21-9. doi: 10.1177/000841740507200107

[9] Flynn S, Palma P, Bender A. Low tech virtual reality improves function in individuals with central nervous system injury. Journal of Neurologic Physical Therapy. 2006; 30(4):210-1. doi: 10.1097/01.npt.0000281304.16905.61

[10] Rahman SA, Rahman A. Efficacy of virtual reality based therapy on balance in children with Down syndrome. World Applied Sciences Journal. 2010; 10(3):254-61.

[11] Salem Y, Gropack SJ, Coffin D, Godwin EM. Effectiveness of a low cost virtual reality system for children with developmental delay: A preliminary randomised single blind controlled trial. Physiotherapy. 2012; 98(3):189-95. doi: 10.1016/j. physio.2012.06.003

[12] Radtka S, Hone R, Brown C, Mastick J, Melnick ME, Dowling GA. Feasibility of computer based videogame therapy for children with cerebral palsy. Games for Health Journal . 2013; 2(4):222-8. doi: 10.1089/g4h.2012.0071

[13] Broeren J, Rydmark M, Sunnerhagen KS. Virtual reality and haptics as a training device for movement rehabilitation after stroke: A single case study. Archives of Physical Medicine and Rehabilitation. 2004; 85(8):1247-50. doi: 10.1016/j. apmr.2003.09.020

[14] Yang S, Hwang WH, Tsai YC, Liu FK, Hsieh LF, Chern JS Improving balance skills in patients who had stroke through virtual reality treadmill training. American Journal of Physical Medicine \& Rehabilitation. 2011; 90(12):969-78. doi: $10.1097 / \mathrm{phm} .0 \mathrm{~b} 013 \mathrm{e} 3182389 \mathrm{fae}$

[15] Yen CY, Lin KH, Hu MH, Wu RM, Lu TW, Lin CH. Effects of virtual reality augmented balance training on sensory organization and attentional demand for postural control in people with Parkinson disease: A randomized controlled trial. Physical Therapy. 2011; 91(6):862-74. doi: 10.2522/ ptj.20100050

[16] Gutiérrez RO, Galán del Río F, Cano de la Cuerda R, Diego A, Isabel M, González RA, et al. A telerehabilitation program by virtual reality-video games improves balance and postural control in multiple sclerosis patients. NeuroRehabilitation. 2013; 33(4):545-54. doi: 10.3233/NRE-130995.
[17] Tatla SK, Radomski A, Cheung J, Maron M, Jarus T. Wii-habilitation as balance therapy for children with acquired brain injury. Developmental Neurorehabilitation. 2012; 17(1):1-15. doi: 10.3109/17518423.2012.740508

[18] Luna Oliva L, Ortiz Gutiérrez RM, Cano de la Cuerda R, Piédrola RM, Alguacil Diego IM, Sánchez Camarero C, et al. Kinect Xbox 360 as a therapeutic modality for children with cerebral palsy in a school environment: a preliminary study. NeuroRehabilitation. 2013; 33(4):513-21.

[19] Deutsch JE, Borbely M, Filler J, Huhn K, Guarrera Bowlby $\mathrm{P}$. Use of a low cost, commercially available gaming console (wii) for rehabilitation of an adolescent with cerebral palsy. Physical Therapy. 2008; 88(10):1196-207. doi: 10.2522/ ptj.20080062

[20] Gil Gómez JA, Lloréns R, Alcañiz M, Colomer C. Effectiveness of a Wii balance board based system (eBaViR) for balance rehabilitation: A pilot randomized clinical trial in patients with acquired brain injury. Journal of NeuroEngineering and Rehabilitation . 2011; 8(1):30. doi: 10.1186/1743-0003-8-30

[21] Williams EN, Carroll SG, Reddihough DS, Phillips BA Galea MP. Investigation of the timed "Up \& Go" test in children. Developmental Medicine \& Child Neurology. 2007; 47(8):518-24. doi: 10.1111/j.1469-8749.2005.tb01185.x

[22] Gan SM, Tung LC, Tang YH, Wang CH. Psychometric properties of functional balance assessment in children with cerebral palsy. Neurorehabilitation and Neural Repair. 2008; 22(6):745-53. doi: $10.1177 / 1545968308316474$

[23] Thompson P, Beath T, Bell J, Jacobson G, Phair T, Salbach $\mathrm{NM}$, et al. Test-retest reliability of the 10-metre fast walk test and 6-minute walk test in ambulatory school-aged children with cerebral palsy. Developmental Medicine \& Child Neurology. 2008; 50(5):370-6. doi: 10.1111/j.1469-8749.2008.02048.x

[24] Chrysagis N, Skordilis EK, Koutsouki D. Validity and clinical utility of functional assessments in children with cerebral palsy. Archives of Physical Medicine and Rehabilitation. 2014; 95(2):369-74. doi: 10.1016/j.apmr.2013.10.025

[25] Bartlett D, Birmingham T. Validity and reliability of a pediatric reach test. Pediatric Physical Therapy. 2003; 15(2):84-90 doi: 10.1097/01.pep.0000067885.63909.5c

[26] Flegel J, HA Kolobe T. Predictive validity of the test of infant motor performance as measured by the Bruininks Oseretsky test of motor proficiency at school age. Physical Therapy. 2002; 82(8):762-71. PMID: 12147006

[27] Biometrics Ltd Catalogue. Operating Manual E-LINK evaluation \& Exercise systems. Newport: Biometrics Ltd. 2012.

[28] Hartveld A, Hegarty J. Frequent weightshift practice with computerised feedback by cerebral palsied children - four single-case experiments. Physiotherapy. 1996; 82(10):573-80. doi: 10.1016/s0031-9406(05)66300-6

[29] Jelsma J, Pronk M, Ferguson G, Jelsma Smit D. The effect of the Nintendo Wii Fit on balance control and gross motor function of children with spastic hemiplegic cerebral palsy. Developmental Neurorehabilitation. 2012; 16(1):27-37. doi 10.3109/17518423.2012.711781

[30] Brien M, Sveistrup H. An intensive virtual reality program improves functional balance and mobility of adolescents with 
cerebral palsy. Pediatric Physical Therapy. 2011; 23(3):258-66. doi: $10.1097 /$ pep.0b013e318227ca0f

[31] Siconolfi Morris GC. Use of a video game based balance training intervention on the balance and function of children with developmental disabilities [PhD Dissertation]. Lexington: University of Kentucky; 2012.

[32] Ramstrand N, Lygnegård F. Can balance in children with cerebral palsy improve through use of an activity promoting computer game. Technology and Health Care. 2012; 20(6):531-40.

[33] Nagano A, Komura T, Fukashiro S. Optimal coordination of maximal effort horizontal and vertical jump motions: A computer simulation study. BioMedical Engineering OnLine. 2007; 6(1):20. doi: 10.1186/1475-925x-6-20

[34] Samozino P, Morin J-B, Hintzy F, Belli A. Jumping ability: A theoretical integrative approach. Journal of Theoretical Biology. 2010; 264(1):11-8. doi: 10.1016/j.jtbi.2010.01.021

[35] Liao HF, Jeny SF, Lai JS, Cheng CK, Hu MH. The relation between standing balance and walking function in children with spastic diplegic cerebral palsy. Developmental Medicine \& Child Neurology. 2008; 39(2):106-12. doi: 10.1111/j.14698749.1997.tb07392.x 